\begin{tabular}{|l|l|l||}
\hline \multicolumn{2}{|c|}{ PublisherInfo } \\
\hline \hline PublisherName & $:$ & BioMed Central \\
\hline \hline PublisherLocation & $:$ & London \\
\hline \hline PublisherImprintName & $:$ & BioMed Central \\
\hline \hline
\end{tabular}

\title{
Percutaneous balloon fenestration and stenting in acute aortic dissection
}

\begin{tabular}{|l|l|l||}
\hline \multicolumn{2}{|c||}{ ArticleInfo } \\
\hline \hline ArticleID & $:$ & 4084 \\
\hline \hline ArticleDOI & $:$ & $10.1186 /$ ccf-1999-1282 \\
\hline \hline ArticleCitationID & $:$ & 1282 \\
\hline \hline ArticleSequenceNumber & $:$ & 21 \\
\hline \hline ArticleCategory & $:$ & Paper Report \\
\hline ArticleFirstPage & $:$ & 1 \\
\hline \hline ArticleLastPage & $:$ & 4 \\
\hline \hline & & RegistrationDate : 1999-8-3 \\
ArticleHistory & $:$ & OnlineDate $\quad$ 1999-8-3 \\
\hline \hline ArticleCopyright & $:$ & Current Science Ltd1999 \\
\hline \hline ArticleGrants & $:$ & \\
\hline \hline ArticleContext & $:$ & 130541111 \\
\hline \hline
\end{tabular}




\section{Keywords}

Aortic dissection, stenting, interventional radiology, ischemic complications

\section{Comments}

This paper shows encouraging results in a relatively large series using endovascular stenting. The technique would appear to have potential for preventing major surgery and consequent intensive care time for patients with ischaemic complications, particularly those with type B dissections. However it is note worthy that the mortality in this series was still $25 \%$, there was a $7.5 \%$ incidence of major complications arising from the procedure, and the overall complication rate was $22.5 \%$. The timing of the technique should be further evaluated, as any effort at improving gut and renal perfusion perioperatively may well impact on the intensive care resources required postoperatively.

\section{Introduction}

Acute aortic dissection often leads to organ ischemia and has a high mortality rate. Reperfusion, by percutaneous means and radiological guidance, is evolving as a means of improving outcome.

\section{Aims}

This paper reports the authors experience of percutaneous fenestration and endovascular stenting at Stanford University School of Medicine over the past six years.

\section{Methods}

Forty patients with acute peripheral ischemic complications of acute dissecting aortic aneurysms underwent percutaneous treatment. Ten patients had type A dissections and nine of these had undergone prior aortic surgery, 30 patients had type B dissections. Ischemia involved the renal $(n=30)$, lower limb 
$(n=22)$, mesenteric $(n=18)$ and upper limb $(n=1)$ circulation. The series was not randomised and treatment was on a compassionate-use basis. Stents were placed from the true lumen of the aorta in preference to the false lumen, and aortic stents were used if the true lumen was collapsed. Balloon fenestration was performed using fluoroscopic guidance to provide flow to the lower limbs. This was coupled with stenting when flow was inadequate.

\section{Results}

Fourteen patients were treated with stenting and balloon fenestration, 24 with stenting alone and two with fenestration alone. The size of the stents varied from $5 \mathrm{~mm}$ in renal vessels to $25 \mathrm{~mm}$ in the aorta. Flow was successfully restored to the ischemic area in 37 of 40 patients (93\%). Of the three remaining patients one had mesenteric obstruction and the superior mesenteric artery could not be cannulated, another had thrombus obstructing the iliac vessels, and a third had limb and small bowel ischemia and died of multiple organ failure following amputation of her right leg. Ten patients died within three days of the procedure (25\%); six of multiple organ failure, two from rupture of the false lumen, one from right heart failure (due to dissection involving the right coronary artery) and one from complications following surgery. Five patients died later, one from of rupture of the false lumen and four from unrelated or unknown causes. There were nine procedure related complications three of which had clinically important outcomes. There was one case of renal artery thrombosis leading to atrophy of the kidney, one of embolic occlusion of the posterior tibial artery leading to amputation and one of $S$. aureussepsis.

\section{Discussion}

Acute aortic dissection carries a high mortality rate which increases to around $80 \%$ when peripheral ischemic complications are present. The evolution of percutaneous techniques has the potential to revascularize ischemic regions without the necessity for major surgery. The authors experience with aortic dissection leads them to suggest that renal and visceral ischemia are independent risk factors for poor outcome. In this series, patients with multiple ischaemic regions had a higher risk of mortality. The authors note the difficulties in drawing any comparison between this series and surgical data, as the patient groups are very different, and additionally it was sometimes necessary to perform the percutaneous technique in addition to surgery (eg type A dissections). Fenestration of the intimal flap can successfully relieve the ischemia; however, some of these patients still require amputation or bowel resection, emphasizing the need for vigilance to determine ischemia at an early stage. Debate exists as to the optimal timing of the percutaneous procedure, whether it should be immediately before surgery to preserve organ function or follow surgical repair. Potential flaws in the study include, treatment of vascular beds that may not have been under threat, the limited time of follow-up and the small number of patients. 


\section{References}

1. Slonim SM, Miller DC, Mitchell RS, Semba CP, Razavi MK, Dake MD: Percutaneous balloon fenestration and stenting for life threatening ischemic complications in patients with acute aortic dissection. J Thorac Cardiovasc Surg . 1999, 117: 1118-1127.

This PDF file was created after publication. 